\title{
Circulating endothelial cells are an early predictor in renal cell carcinoma for tumor response to sunitinib
}

\author{
Viktor Gruenwald1, Gernot Beutel', Susanne Schuch-Jantsch, Christoph Reuter ${ }^{1}$, Philipp Ivanyi ${ }^{1}$, Arnold Ganser ${ }^{1}$,
} Marion Haubitz ${ }^{2}$

\begin{abstract}
Background: Tyrosine kinase inhibitors (TKI) have enriched the therapeutic options in patients with renal cell carcinoma (RCC), which frequently induce morphological changes in tumors. However, only little is known about the biological activity of TKI. Circulating endothelial cells (CEC) have been associated with endothelial damage and, hence, may serve as a putative marker for the biological activity of TKI. The main objective of our study was to evaluate the predictive value of CEC, monocytes, and soluble vascular endothelial growth factor receptor (sVEGFR)2 in RCC patients receiving sunitinib treatment.
\end{abstract}

Methods: Analyses of CEC, monocytes, and SVEGFR-2 were accomplished for twenty-six consecutive patients with metastatic RCC who received treatment with sunitinib (50 mg, 4 wks on 2 wks off schedule) at our institution in 2005 and 2006.

Results: In RCC patients CEC are elevated to $49 \pm 44 / \mathrm{ml}$ (control $8 \pm 8 / \mathrm{ml} ; \mathrm{P}=0.0001$ ). Treatment with sunitinib is associated with an increase in CEC within 28 days of treatment in patients with a Progression free survival (PFS) above the median to $111 \pm 61(P=0.0109)$, whereas changes in patients with a PFS below the median remain insignificant $69 \pm 61 / \mathrm{ml}(P=0.1848)$. Monocytes and sVEGFR2 are frequently altered upon sunitinib treatment, but fail to correlate with clinical response, defined by PFS above or below the median.

Conclusions: Sunitinib treatment is associated with an early increase of CEC in responding patients, suggesting superior endothelial cell damage in these patients as a putative predictive biomarker.

\section{Background}

Tyrosine kinase inhibitors (TKI) were recently successfully added to the armentarium to treat renal cell carcinoma (RCC). Sunitinib, a first generation TKI which targets VEGFR1-3, PDGFR $\alpha / \beta$, KIT, RET, CSF 1R and FLT-3, has recently been approved for the treatment of RCC [1]. Its antitumor activity is at least partially mediated through inhibition of tumor vessel formation, which can be demonstrated through sophisticated imaging techniques, such as dynamic contrast enhanced MRI. As these techniques are not commonly available to most physicians, biomarkers which predict biological

\footnotetext{
* Correspondence: Gruenwald.Viktor@MH-Hannover.de

${ }^{1}$ Hannover Medical School, Carl-Neuberg-Strasse 1, 30625 Hannover, Germany Clinic for Hematology, Hemostasis, Oncology and Stem Cell transplantation

Full list of author information is available at the end of the article
}

and antitumor activity are desperately needed to adequately monitor tumor therapy and predict tumor response to sunitinib.

In RCC, inhibition of vessel formation is thought to be the prime mechanism to achieve antitumor activity [2]. The biological relevance of the different VEGFR family members in this process was elucidated in murine models, and VEGFR-2 was determined to be the main regulator of neo-angiogenesis and the most promising target for therapeutic intervention [3]. Various activating ligands were identified, which may bind with a distinct affinity to VEGFR family members. Inhibition of these targets correlated with significant changes of circulating proteins and the application of sunitinib was associated with changes of circulating VEGF, placental growth factor (PIGF) and sVEGFR-2 [4-6]. So far, such changes
C Biomed Central

(c) 2010 Grunwald et al; licensee BioMed Central Ltd. This is an Open Access article distributed under the terms of the Creative Commons Attribution License (http://creativecommons.org/licenses/by/2.0), which permits unrestricted use, distribution, and reproduction in any medium, provided the original work is properly cited. 
were associated with target inhibition in vivo but failed to predict tumor response in patients $[4,7]$.

Other markers, such as circulating endothelial cells (CEC), have been studied in order to define the biological response to these agents. Increased CEC levels were demonstrated to correlate with vascular damage and are observed in a variety of vascular disorders [8-11]. CEC were thought to be shed from the endothelium and successfully predict the activity of vessel damage seen in vasculitis [11]. In cancer patients, elevated CEC levels were also detected [12] and apoptotic CEC were recently proposed to predict clinical outcome of metronomic therapy in breast cancer patients [13]. In addition, the predictive value of soluble markers was studied in treatments with angiogenesis inhibitors. Soluble VEGFR-2 levels were reported to decrease during sunitinib treatment but were not predictive for response in RCC and GIST patients $[4,5]$.

In this pilot study, we investigated the role of CEC and sVEGFR2 as potential biomarkers in metastatic RCC patients who were treated with sunitinib. Blood samples were collected prior to and during the course of sunitinib therapy and tumor response was monitored according to RECIST criteria. Biomarkers were analyzed for responding and non-responding patients either for kinetic changes during the course of treatment or as a single predictive marker prior to drug-exposure.

\section{Methods}

\section{Patients}

The study was conducted in accordance with the Declaration of Helsinki and the local Institutional Review Board approved the study protocol. Informed consent was obtained prior to blood collections. 26 patients with metastatic RCC were included in the analyses (Table 1).

Best response to therapy was defined as either stable disease (SD) or objective response (OR) according to RECIST criteria, and was determined by CT-scans at baseline and every other cycle. Due to limited sample size, responders were defined by either SD or OR, and patients with progressive disease (PD) were deemed non-responders. A total of 6 non-responders and 20 responders were identified within the study population. No patient received treatment with a VEGFR-inhibitor prior to sunitinib. 15 male and 11 female patients entered the study with a mean age of 62 years (range 45-80). 18 patients had received at least one prior regimen and 8 patients were treatment naïve. Blood samples from 20 healthy volunteers with a mean age of 59 (range 45-77) served as normal controls.

\section{Study design}

Blood samples for analyses of CEC, monocytes and sVEGFR2 were collected in parallel in patients who
Table 1 Patients' Characteristics

\begin{tabular}{ccc}
\hline & No. of patients & (\%) \\
\hline ECOG & 24 & 92 \\
$\mathbf{1}$ & 2 & 8 \\
Nephrectomy & 24 & 92 \\
Histology & & \\
Papillary & 2 & 8 \\
Sarcomatoid & 2 & 8 \\
Chromophobe & 1 & 4 \\
clear cell & 21 & \\
Age (range) & $62(45-80)$ years & \\
Male & 15 & \\
Female & 11 & 42 \\
Median PFS in days (range) & $249(63-953)$ & 35 \\
Best response & & 23 \\
Objective response (OR) & 11 & \\
Stable disease (SD) & 9 & \\
Progressive disease (PD) & 6 & \\
\hline
\end{tabular}

received treatment with sunitinib (50 mg OD 4 weeks on - 2 weeks off) for metastatic RCC as standard of care treatment prior to start of treatment, at day 14, day 28 and with the last dose of sunitinib of each subsequent course for the duration of sunitinib therapy. Monocytes were detected according to institutional standard on day 1,14 and 28 during the first cycle and day 1 and/or 28 during subsequent cycles by complete blood counts. The study was performed without external financial support.

\section{Preparation of blood samples}

Blood samples were collected from 26 patients. Available probes at baseline consisted of 26 for CEC, 26 for monocytes and 18 for sVEGFR2 analyses. After 14 days of treatment, 17 probes were assessed for CEC, 23 for monocytes and 14 for sVEGFR2. After 28 days, a total of 23 probes were analyzed for CEC, 22 for monocytes and 17 for sVEGFR2.

Blood samples for CEC analyses were taken and analyzed as previously described [14]. In brief, samples were analyzed within 4 hours of non-traumatic venous puncture in $7.5 \mathrm{ml}$ ethylene-diamine tetra-acetic acid and stored at $4^{\circ} \mathrm{C}$ if readout was not performed immediately. Anti-CD 146-coated M-450 Dynabeads (Dynal, Norway) were prepared as described by the manufacturer. $1 \mathrm{ml}$ blood was mixed with $1 \mathrm{ml}$ buffer (phosphate-buffered saline, $0.1 \%$ bovine serum albumin, $0.1 \%$ sodium azide, and $0.6 \%$ sodium citrate) on ice, supplemented by $20 \mu \mathrm{l}$ of FcR-blocking agent (Miltenyi, Bergisch Gladbach, Germany) and $50 \mu \mathrm{l}$ anti-CD 146-coated Dynabeads (10 $\mu \mathrm{g} \mathrm{ml}^{-1}$ ). Samples were mixed (30 min.) and rinsed with 
buffer inside the magnet at $4^{\circ} \mathrm{C}$ and stained with FITCcoupled Ulex europaeus lectin-1 solution (UEA-1, Sigma-Aldrich, St. Louis, USA) for 1 hour in darkness. CEC were then washed and visualized by fluorescence microscopy at $553 \mathrm{~nm}$, and counted employing a Nageotte chamber. Serum for sVEGFR2 was immediately stored at $-20^{\circ} \mathrm{C}$ and analyzed by ELISA-tests according to manufacturer's description (R\&D Systems, Minneapolis, USA).

\section{Statistical analyses}

Paired and unpaired Student's t-Test were employed for statistical analyses. Paired Student's t-Test has been utilized in groups with repeated measurements all other t-test evaluations consisted of unpaired t-Tests. KaplanMeier estimates were used to plot median progression free survival (PFS). Descriptive statistics are utilized to show the fraction of patients with distinct variables. Standard deviation is reported, if not otherwise specified.

\section{Results}

Patients with metastatic RCC exhibit higher CEC baseline levels than normal controls

A total of 26 patients with metastatic RCC were included in our study. Patients' characteristics are depicted in table 1. In order to evaluate the role of CEC in RCC, we first evaluated values in normal controls and untreated RCC patients. Mean CEC values in metastatic RCC patients were significantly higher than those from normal controls $(49 \pm 44 \mathrm{CEC} / \mathrm{ml}$ vs. $8 \pm 8 \mathrm{CEC} / \mathrm{ml} ; \mathrm{P}=0.0001)$ (Figure 1$)$.

Treatment with sunitinib is associated with an increase of CEC as an early biological response

Sunitinib achieved a median PFS of 249 days (Figure 2), which was associated with response to therapy (OR and

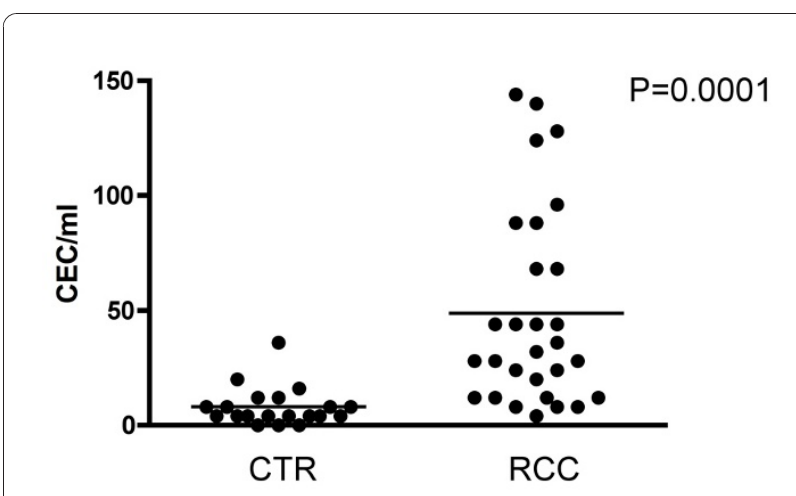

Figure 1 Levels of CEC are elevated in metastatic RCC patients. Baseline levels of CEC in metastatic RCC patients were significantly elevated compared to normal controls $(C T R)(P=0.0001)$. Mean values for CEC were $8 \pm 8$ and $49 \pm 44 / \mathrm{ml}$ in CTR and RCC patients, respectively.

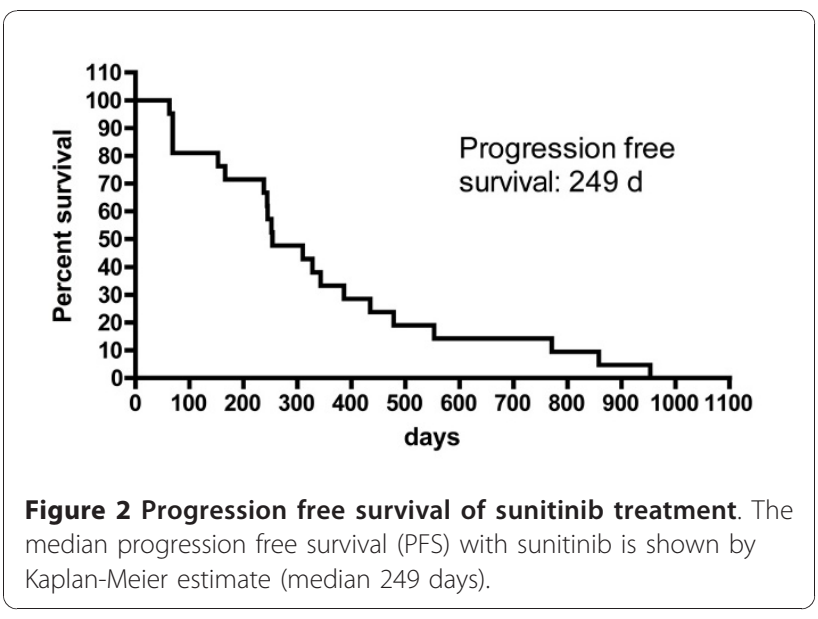

SD) in $77 \%$ of the patients. Clear cell histology $(\mathrm{N}=21)$ was the predominant tumor type and response to therapy was noted in 17 patients (81\%) and median PFS was 254 days. This subgroup of patients achieved baseline CEC counts of $47 \pm 43 / \mathrm{ml}$. However, a distinct subtype was noted in 5 patients (sarcomatoid $\mathrm{N}=2$; papillary $\mathrm{N}=2$; chromophobe $\mathrm{N}=1$ ) and treatment with sunitinib resulted in tumor response (OR or SD) in 3 patients (60\%) and was associated with a median PFS of 156 days. A similar CEC count of $47 \pm 46 / \mathrm{ml}$ was detected in these patients at baseline ( $\mathrm{P}=0.9737)$.

We investigated the kinetics of CEC in patients treated with sunitinib, which is administered over 28 days followed by a 14 day drug holiday. Probes were sampled at baseline, days 14 and 28 during course one and on the last day of drug administration of each course to ensure maximum target inhibition for biological effects. The analyses of all treated patients revealed significant changes after 14 and 28 days of sunitinib treatment. During the first course, mean values increased from 49 $\pm 44 \mathrm{CEC} / \mathrm{ml}$ at baseline to $84 \pm 59 \mathrm{CEC} / \mathrm{ml}$ after 14 days $(\mathrm{P}=0.0331)$ and $89 \pm 63 \mathrm{CEC} / \mathrm{ml}$ after 28 days $(\mathrm{P}$ $=0.0159)$ of treatment. CEC declined during the subsequent treatment to baseline levels and below (range 19-58 CEC/ml). The course of CEC during sunitinib treatment is depicted in a subset of patients $(\mathrm{N}=13)$ for whom repeated measures were available for the duration of 238 days (Figure 3A).

To further define whether early CEC increase has a predictive value for sunitinib treatment, we explored CEC changes in subgroups of patients with a PFS above or below the median PFS. An increased number of CEC is thought to be associated with vascular damage, which we considered a favorable early biological response to sunitinib. We therefore analyzed CEC values during the first course of treatment.

Increased CEC numbers were observed in patients who had a PFS above the median. In these patients, 
A)
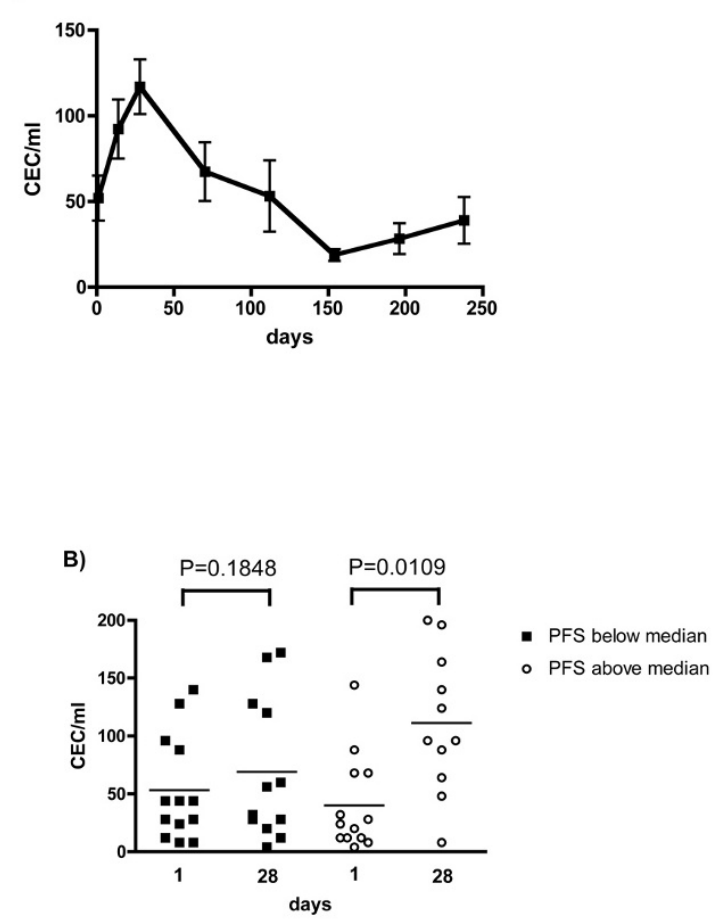

Figure 3 CEC display a characteristic response to treatment with sunitinib. A) Characteristic changes of CEC counts are depicted in 13 patients with repeated measures for the duration of 238 days. Curve shows a marked increase within 28 days, followed by decreased CEC counts to a basal level. Bars show mean standard error mean. B) Patients were grouped according to their PFS above or below the median. CEC measured at baseline and after 28 days of treatment with sunitinib are depicted for both groups. In patients with PFS above the median mean CEC values increased significantly from baseline $40 \pm 41 \mathrm{CEC} / \mathrm{ml}$ to $111 \pm 61(P=0.0109)$ at day 28 . However, in patients with PFS below the median, the increase from $53 \pm 45$ to $69 \pm 61 \mathrm{CEC} / \mathrm{ml}$ remained insignificant $(P=0.1848)$.

mean CEC values increased from $40 \pm 41 \mathrm{CEC} / \mathrm{ml}$ at baseline to $111 \pm 61 \mathrm{CEC} / \mathrm{ml}$ at day $28(\mathrm{P}=0.0109)$ (Figure 3B). In addition, early assessment at day 14 was performed in 13 patients and showed a similar increase in mean values to $93 \pm 63 \mathrm{CEC} / \mathrm{ml}(\mathrm{P}=0.0067)$. In contrast, patients who achieved a median PFS below the median exhibited no significant alteration of CEC (53 $\pm 45 \mathrm{CEC} / \mathrm{ml}$ at baseline, $69 \pm 61 \mathrm{CEC} / \mathrm{ml}$ at day 28 ; $\mathrm{P}=0.1848$ ), supporting the notion that CEC increase may represent a valuable marker for clinical activity (Figure 3B). Early assessment at day 14 was available in 5 patients only. However, in these patients early assessment was associated with an insignificant increase of mean $\mathrm{CEC}$ values to $83 \pm 30 \mathrm{CEC} / \mathrm{ml}(\mathrm{P}=0.3659)$.

While, baseline values of CEC prior to drug exposure showed a trend to lower values $(40 \pm 41 \mathrm{CEC} / \mathrm{ml})$ in patients with a PFS above the median when compared to patients with a PFS below the median $(53 \pm 45 \mathrm{CEC} /$ $\mathrm{ml}$ ), these differences remained insignificant $(\mathrm{P}=$ 0.4414 ) and do not explain treatment outcome as a single pre-dose evaluation.

\section{Monocyte counts change in response to sunitinib}

VEGFR-1 promotes vessel growth through recruitment of monocytic blood cells [15], including endothelial progenitor cells (EPC). Monocytes express VEGFR-1 [16] and hence may represent a convenient surrogate marker to measure sunitinib's biological activity. Sunitinib treatment resulted in significant decrease of mean monocyte values from $594 \pm 192 / \mu \mathrm{l}$ prior to treatment to $312 \pm$ $136 / \mu \mathrm{l}$ and $278 \pm 122 / \mu \mathrm{l}$ at 14 and 28 days of treatment, respectively (Figure 4A). Washout of sunitinib after the first and second treatment course was associated with an increase of monocytes to baseline levels of $501 \pm$ $178 / \mu \mathrm{l}$ and $467 \pm 186 / \mu \mathrm{l}$, respectively, indicating reversible target inhibition. Monocyte response was sustained upon repeated challenge with sunitinib for 28 days (265 $\pm 108 / \mu \mathrm{l})$.

All patients showed a similar decline of monocyte counts, irrespective of the duration of PFS to sunitinib. Both groups showed a significant decrease of monocytes on day $28[\mathrm{P}=0.0006$ (below median); $\mathrm{P}<0.0001$ (above median)]. However, monocyte values at day 14 and 28 were similar in both groups $(\mathrm{P}=0.2070$, $\mathrm{P}=0.3006$, respectively) (Figure $4 \mathrm{~B}$ ).

\section{Treatment with sunitinib is associated with decreased sVEGFR2, but its kinetic change fails to predict clinical response}

sVEGFR2 was investigated as a potential predictive biomarker for response to sunitinib treatment. The mean sVEGFR2 concentration prior to treatment was $13317 \pm$ $3017 \mathrm{pg} / \mathrm{ml}$. Sunitinib induced a 39\% reduction of sVEGFR2 (to $8180 \pm 2301 \mathrm{pg} / \mathrm{ml} ; \mathrm{P}<0.0001$ ), which remained repressed throughout further treatment. The pattern of sVEGFR2 response is illustrated in Figure 5A in patients with repeated measurement available for 70 days only. In these patients, sVEGFR2 dropped significantly at day $28(\mathrm{P}<0.0001)$ compared to baseline.

We then investigated subgroups of patients according to their PFS to sunitinib, which was either above or below the median. Mean sVEGFR2 levels prior to treatment with sunitinib showed a trend for decreased counts in patients with a PFS above the median $(11724 \pm 2278$ $\mathrm{pg} / \mathrm{ml}$ ) compared to patients with a PFS below the median $(14615 \pm 4068 \mathrm{pg} / \mathrm{ml})$, however, the difference remained insignificant $(P=0.0814)$. Both groups showed similar decrease of sVEGFR2 during the latter course of treatment (day 28: $7157 \pm 1800 \mathrm{pg} / \mathrm{ml}$ and $8484 \pm 3737$ $\mathrm{pg} / \mathrm{ml}$, respectively; $\mathrm{P}=0.3760$ ) (Figure $5 \mathrm{~B}$ ). 


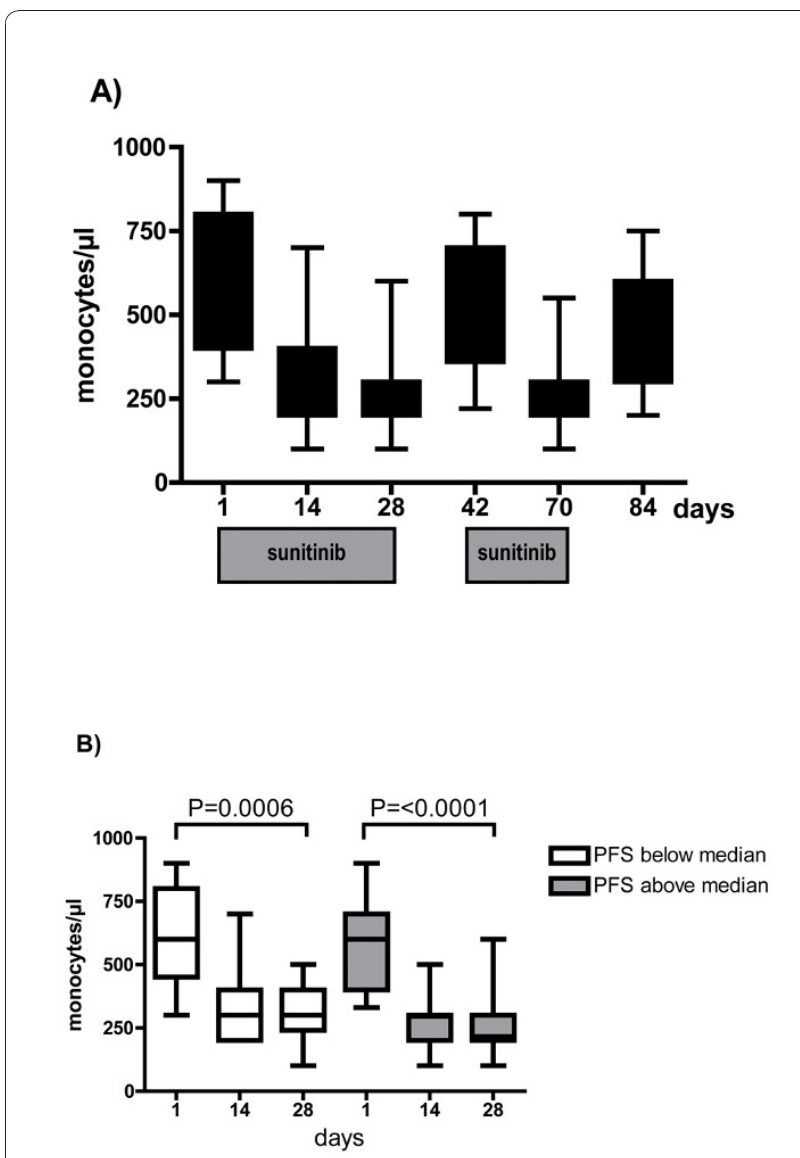

Figure 4 Treatment with sunitinib decreases circulating monocytes in all treated patients, irrespective of their clinical response to treatment. A) Monocytes decrease during repeated exposure to sunitinib. However, increased values are measured after the 2-weeks washout interval of sunitinib. B) Patients were grouped according to PFS above or below the median. In both groups, monocyte counts decrease significantly from baseline to day $28[P$ $=0.0006$ (below median); $\mathrm{P}<0.0001$ (above median)]. However, monocyte counts at day 1 and 28 remained similar between both groups $[P=0.5701$ (day 1), $P=0.3006$ (day 28), respectively].

\section{Discussion}

Targeted agents have recently enriched the treatment of renal cell carcinoma. Objective responses are frequently seen in patients receiving targeted agents and approach $40 \%$ for patients treated with sunitinib [1]. However, best objective responses often occur rather late during the course of treatment with VEGFR-inhibitors. Axitinib, a potent inhibitor of VEGFR, showed an objective response in $44 \%$ of RCC patients [17], which were registered after 90-403 days of continuous treatment. Two complete responses were detected at days 256 and 362, respectively. Clearly, there is a need to identify biological markers, which allow earlier prediction of tumor response to anti-angiogenesis agents. Numerous markers were recognized to be altered through sunitinib

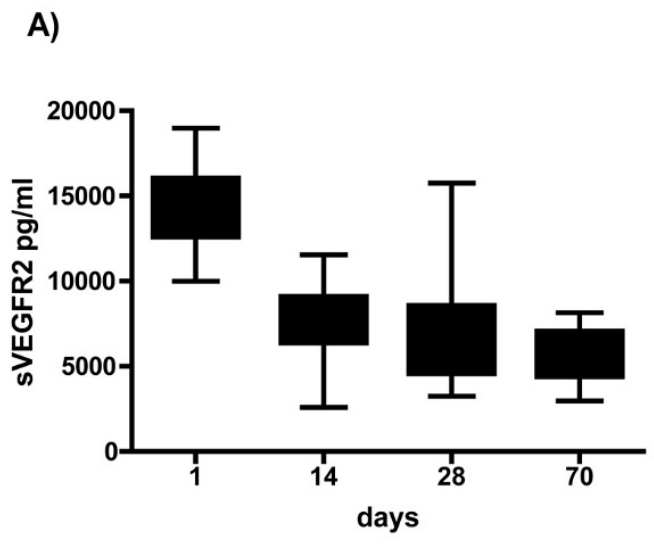

B)

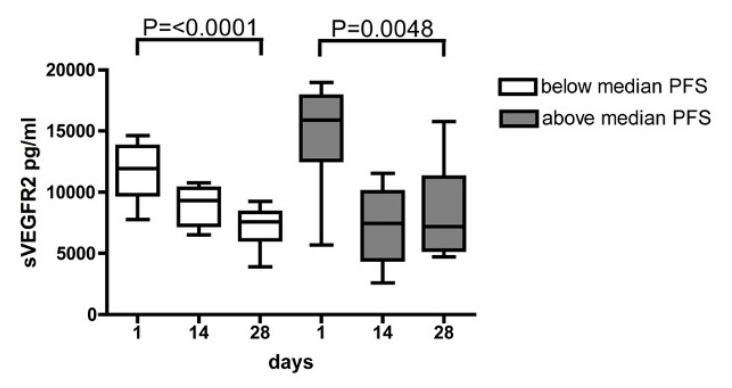

Figure 5 sVEGFR2 is a sensitive biomarker for sunitinib treatment but fails to predict clinical response. A) In 16 patients, repeated sVEGFR2 measurements were performed on days 1 - 70. SVEGFR2 declines significantly during treatment with sunitinib (day 28: $P<0.0001$ ). B) Patients were grouped according to PFS above or below the median. Compared to baseline, sVEGFR2 decreased in each group significantly on day $28[\mathrm{P}<0.0001$ (below median), $\mathrm{P}=$ 0.0048 (above median), respectively]. However, no difference was shown at day 28 between both groups $(P=3760)$.

treatment, including VEGFR ligands, soluble receptors and endothelial cells [4-6]. Our work focused on CEC, monocytes and sVEGFR2 in order to elucidate their role as potential predictive markers in RCC patients treated with sunitinib.

Patients with detectable tumors are known to have increased levels of CEC as a consequence of endothelial perturbation, but the implication of this observation for prognosis or tumor response remains unclear [18-20]. Beerepoot et al. reported similar CEC values for healthy controls and patients with SD as best tumor response, whereas patients seemed to have elevated CEC at time of progression [12]. Mancuso et al. reported normal 
levels of CEC in patients with complete remission of lymphoma [19]. Patients in these studies received conventional chemotherapeutics, which target the tumor rather than its vasculature. Hence, it is conceivable that the role of CEC in anti-angiogenic therapies may be different.

The source of CEC remains mainly undetermined. Chang et al [21] suggested a mutual luminal surface of tumor and endothelial tissue in tumor vessels, which contribute to the continuous shedding of circulating cells into the blood stream. Application of therapeutics which target the tumor vessels is thought to alter the compilation of circulating cells and treatments with angiogenesis inhibitors were associated with changes of CEC and EPC in tumor-bearing mice. ZD6126, an inhibitor of VEGFR2, was associated with a dose-dependent increase of CEC and decrease of microvessel density, suggesting that inhibition of angiogenesis is associated with gain of CEC shedding from the tumor vasculature [22].

Currently, the clinical relevance of CEC as a predictive biomarker for anti-angiogenic therapy has only been tested in small series and results remain controversial. In our study, sunitinib treatment was associated with a significant increase of CEC during the initial 4 weeks of treatment in patients who achieved a PFS above the median, whereas patients with a PFS below the median exhibited no significant increase in CEC. These findings are supported by other studies, which also determined significant changes of early biomarkers within 4 weeks of treatment $[4,23]$. Prolonged treatment with sunitinib has been studied in a subgroup of patients with repeated measures only. In these patients CEC counts decline to a basal level with sustained sunitinib treatment. Therefore, we share the notion that the therapy-induced CEC elevation may represent an early marker for superior clinical response to sunitinib.

Some limitations are associated in regard to studies exploring the nature of CEC in patients. Different evaluation tools and sampling time points may lead to conflicting results. In the phase II study of pazopanib, an inhibitor of VEGFR1-3, KIT, and PDGFR, evaluation of biomarkers was included at week 12 [24]. CEC showed no correlation with tumor response. Our data supports the notion that CEC may be an early marker, which must be determined within 4 weeks of therapy initiation in order to observe biological activity. The mere detection of CEC counts obviously raises numerous questions and awaits the development of a more detailed view to CEC function and vitality, such as analyses of apoptosis or endothelial cell activation.

We also investigated the potential of circulating monocytes and sVEGFR2 as putative surrogate markers to assess sunitinib's biological activity. Monocytes are known to express VEGFR1, KIT, and PDGFR and, thus, may reflect a valuable tool to monitor target inhibition. Treatment with sunitinib resulted in a marked decrease of monocyte counts in all patients, which may suggest adequate target inhibition through sunitinib irrespective of their clinical response to treatment. As a consequence of target inhibition, a marked proportional decrease of monocytes has also been previously reported by other investigators [4]. In addition, neutrophils and monocytes have been shown to be elevated in non-responding RCC patients treated with sunitinib [25]. These studies underscore the role of monocytes in the process of response to sunitinib and warrant further studies.

Treatment with sunitinib correlated with increased VEGF and decreased sVEGFR2 in patient serum, but correlation with clinical outcome remained mainly undefined [26-28]. In breast cancer patients, only decreased sVEGFR3 and sKIT were thought to correlate with clinical outcome [13]. In RCC patients, no correlation for VEGF, sVEGFR2, sVEGFR3 and efficacy could be determined [29]. Our results support the notion that sunitinib-induced target inhibition is associated with decreased sVEGFR2 concentrations, but the kinetic modulation of sVEGFR2 levels is insufficient to predict tumor response throughout the course of therapy.

Our results underline the importance of the incorporation of biological markers in anti-angiogenic therapies in order to precisely determine the response to therapy. The increase of CEC may represent a valuable tool to predict biological response in RCC patients undergoing sunitinib treatment, but time of analysis seems to be crucial in order to detect the clinical relevance of CEC numbers. The small sample size in our analyses hampers the applicability of our results to the clinic and requires further careful validation. Clearly, there is still no single, magic predictive marker for antiangiogenic therapy. Rather, a panel of biomarkers has to be considered in order to obtain a detailed picture of the effectiveness of the given therapy. Our findings suggest that CEC may be a valuable biomarkers to predict superior PFS response to sunitinib.

\section{Conclusions}

Early increase of circulating endothelial cells is associated with superior PFS response to sunitinib and may serve as an early predictive biomarker. However, monocytes and sVEGFR-2 may exert pharmacodynamic changes, but fail to correlate with PFS of sunitinib treatment. Further prospective studies are needed to determine the role of soluble markers in RCC.

\section{Acknowledgements}

The authors thank Michael A. Morgan for critically reading the manuscript. 


\section{Author details}

'Hannover Medical School, Carl-Neuberg-Strasse 1, 30625 Hannover, Germany Clinic for Hematology, Hemostasis, Oncology and Stem Cell transplantation. ${ }^{2}$ Hannover Medical School, Carl-Neuberg-Strasse 1, 30625 Hannover, Germany Department of Nephrology.

\section{Authors' contributions}

VG drafted the manuscript and design of the study, collected and analyzed the clinical data and correlated with biomarker data. GB co-drafted the design of the study and coordinated specimen collection. SSJ carried out soluble biomarker tests. CR and PI collected, gathered and coordinated clinical data. AG provided general support and helped to draft the manuscript. MH planned and conducted the analyses of CEC and participated in the design of the study. All authors read and approved the manuscript.

\section{Competing interests}

Viktor Grünwald received consultancy and honoraria from Pfizer Oncology, Roche Pharma, GSK and Novartis Oncology. A research grant was provided by Wyeth Oncology and lecture honoriarium from Bayer. The following authors did not declare any competing interest: Gernot Beutel, Susanne Schuch-Jantsch, Christoph Reuter, Philipp Ivanyi, Arnold Ganser, and Marion Haubitz.

Received: 7 July 2009 Accepted: 31 December 2010 Published: 31 December 2010

\section{References}

1. Motzer RJ, Hutson TE, Tomczak P, Michaelson MD, Bukowski RM, Rixe O, Oudard S, Negrier S, Szczylik C, Kim ST, et al: Sunitinib versus interferon alfa in metastatic renal-cell carcinoma. N Engl J Med 2007, 356(2):115-124.

2. Rini BI, Small EJ: Biology and clinical development of vascular endothelial growth factor-targeted therapy in renal cell carcinoma. J Clin Oncol 2005, 23(5):1028-1043

3. Olsson AK, Dimberg A, Kreuger J, Claesson-Welsh L: VEGF receptor signalling - in control of vascular function. Nat Rev Mol Cell Biol 2006, 7:359-371

4. Norden-Zfoni A, Desai J, Manola J, Beaudry P, Force J, Maki R, Folkman J, Bello CL, Baum CM, Deprimo SE, et al: Blood-based biomarkers of SU11248 activity and clinical outcome in patients with metastatic imatinib-resistant gastrointestinal stromal tumor. Clin Cancer Res 2007, 13:2643-2650

5. Deprimo SE, Bello CL, Smeraglia J, Baum CM, Spinella D, Rini Bl, Michaelson MD, Motzer RJ: Circulating protein biomarkers of pharmacodynamic activity of sunitinib in patients with metastatic renal cell carcinoma: modulation of VEGF and VEGF-related proteins. Journal of translational medicine 2007, 5:32.

6. Ebos JM, Lee CR, Christensen JG, Mutsaers AJ, Kerbel RS: Multiple circulating proangiogenic factors induced by sunitinib malate are tumor-independent and correlate with antitumor efficacy. Proc Natl Acad Sci USA 2007, 104:17069-17074.

7. Motzer RJ, Michaelson MD, Redman BG, Hudes GR, Wilding G, Figlin RA, Ginsberg MS, Kim ST, Baum CM, DePrimo SE, et al: Activity of SU11248, a multitargeted inhibitor of vascular endothelial growth factor receptor and platelet-derived growth factor receptor, in patients with metastatic renal cell carcinoma. J Clin Oncol 2006, 24(1):16-24.

8. Woywodt A, Schroeder M, Gwinner W, Mengel M, Jaeger M, Schwarz A, Haller $\mathrm{H}$, Haubitz M: Elevated numbers of circulating endothelial cells in renal transplant recipients. Transplantation 2003, 76(1):1-4.

9. Woywodt A, Schroeder M, Mengel M, Schwarz A, Gwinner W, Haller H, Haubitz M: Circulating endothelial cells are a novel marker of cyclosporine-induced endothelial damage. Hypertension 2003, 41(3 Pt 2):720-723.

10. Woywodt A, Scheer J, Hambach L, Buchholz S, Ganser A, Haller H, Hertenstein B, Haubitz M: Circulating endothelial cells as a marker of endothelial damage in allogeneic hematopoietic stem cell transplantation. Blood 2004, 103(9):3603-3605.

11. Mutin M, Canavy I, Blann A, Bory M, Sampol J, Dignat-George F: Direct evidence of endothelial injury in acute myocardial infarction and unstable angina by demonstration of circulating endothelial cells. Blood 1999, 93(9):2951-2958.
12. Beerepoot LV, Mehra N, Linschoten F, Jorna AS, Lisman T, Verheul HM, Voest EE: Circulating endothelial cells in cancer patients do not express tissue factor. Cancer Lett 2004, 213:241-248.

13. Burstein HJ, Elias AD, Rugo HS, Cobleigh MA, Wolff AC, Eisenberg PD, Lehman M, Adams BJ, Bello CL, Deprimo SE, et al: Phase II study of sunitinib malate, an oral multitargeted tyrosine kinase inhibitor, in patients with metastatic breast cancer previously treated with an anthracycline and a taxane. J Clin Oncol 2008, 26:1810-1816.

14. Woywodt A, Blann AD, Kirsch T, Erdbruegger U, Banzet N, Haubitz M, Dignat-George F: Isolation and enumeration of circulating endothelial cells by immunomagnetic isolation: proposal of a definition and a consensus protocol. J Thromb Haemost 2006, 4(3):671-677.

15. Luttun A, Tjwa M, Moons L, Wu Y, Angelillo-Scherrer A, Liao F, Nagy JA, Hooper A, Priller J, De Klerck B, et al: Revascularization of ischemic tissues by PIGF treatment, and inhibition of tumor angiogenesis, arthritis and atherosclerosis by anti-Flt1. Nat Med 2002, 8(8):831-840.

16. Sawano A, Iwai S, Sakurai Y, Ito M, Shitara K, Nakahata T, Shibuya M: Flt-1, vascular endothelial growth factor receptor 1 , is a novel cell surface marker for the lineage of monocyte-macrophages in humans. Blood 2001, 97(3):785-791.

17. Rixe O, Bukowski RM, Michaelson MD, Wilding G, Hudes GR, Bolte O, Motzer RJ, Bycott PW, Liau KF, Freddo J, et al: Axitinib treatment in patients with cytokine-refractory metastatic renal-cell cancer: a phase II study. Lancet Oncol 2007, 8:975-984.

18. Bhatt RS, Norden-Zfoni A, O'Neill A, Zurita AJ, Wu H, Prox D, Atkins MB, Heymach JV: Circulating endothelial cells are a potential biomarker for patients with renal cell carcinoma (RCC) with and without von Hippel Lindau (VHL) syndrome. J Clin Oncol 2008, 26(Suppl):Abstr 5098.

19. Mancuso P, Burlini A, Pruneri G, Goldhirsch A, Martinelli G, Bertolini F: Resting and activated endothelial cells are increased in the peripheral blood of cancer patients. Blood 2001, 97(11):3658-3661.

20. Monestiroli S, Mancuso P, Burlini A, Pruneri G, Dell'Agnola C, Gobbi A, Martinelli G, Bertolini F: Kinetics and viability of circulating endothelial cells as surrogate angiogenesis marker in an animal model of human lymphoma. Cancer Res 2001, 61:4341-4344.

21. Chang YS, di Tomaso E, McDonald DM, Jones R, Jain RK, Munn LL: Mosaic blood vessels in tumors: frequency of cancer cells in contact with flowing blood. Proc Natl Acad Sci USA 2000, 97:14608-14613.

22. Beaudry P, Force J, Naumov GN, Wang A, Baker CH, Ryan A, Soker S, Johnson BE, Folkman J, Heymach JV: Differential effects of vascular endothelial growth factor receptor-2 inhibitor ZD6474 on circulating endothelial progenitors and mature circulating endothelial cells: implications for use as a surrogate marker of antiangiogenic activity. Clin Cancer Res 2005, 11:3514-3522.

23. Vroling L, van der Veldt AA, de Haas RR, Haanen JB, Schuurhuis GJ, Kuik DJ, van Cruijsen H, Verheul HM, van den Eertwegh AJ, Hoekman K, et al: Increased numbers of small circulating endothelial cells in renal cell cancer patients treated with sunitinib. Angiogenesis 2009, 12(1):69-79.

24. Hutson TE, Davis ID, Machiels JH, de Souza PL, Baker K, Bordogna W, Westlund R, Crofts T, Pandite L, Figlin RA: Biomarker analysis and final efficacy and safety results of a phase II renal cell carcinoma trial with pazopanib (GW786034), a multi-kinase angiogenesis inhibitor. J Clin Oncol 2008, 26(Suppl):Abstr 5046

25. van Cruijsen $H$, van der Veldt AA, Vroling L, Oosterhoff $D$, Broxterman $H J$, Scheper RJ, Giaccone G, Haanen JB, van den Eertwegh AJ, Boven E, et al: Sunitinib-induced myeloid lineage redistribution in renal cell cancer patients: CD1c+ dendritic cell frequency predicts progression-free survival. Clin Cancer Res 2008, 14(18):5884-5892.

26. George DJ, Michaelson MD, Rosenberg JE, Bukowski RM, Sosman JA, Stadler WM, Margolin K, Hutson TE, Rini BI: Phase II trial of sunitinib in bevacizumab-refractory metastatic renal cell carcinoma (mRCC): Updated results and analysis of circulating biomarkers. J Clin Oncol ASCO Annual Meeting Proceedings Part I 2007, 25(18s):Abstr 5035.

27. Mallat Z, Benamer H, Hugel B, Benessiano J, Steg PG, Freyssinet JM, Tedgui A: Elevated levels of shed membrane microparticles with procoagulant potential in the peripheral circulating blood of patients with acute coronary syndromes. Circulation 2000, 101:841-843.

28. Bello CL, Deprimo SE, Friece C, Smeraglia J, Sherman L, Tye L, Baum CM, Meropol NJ, Lenz H, Kulke MH: Analysis of circulating biomarkers of sunitinib malate in patients with unresectable neuroendocrine tumors 
(NET): VEGF, IL-8, and soluble VEGF receptors 2 and 3. J Clin Oncol ASCO Annual Meeting Proceedings Part I 2006, 24(18s):abstr 4045.

29. Redman BG, Hudes GR, Kim ST, Chen I, Motzer RJ: Sunitinib in combination with gefitinib in patients (pts) with metastatic renal cell carcinoma (mRCC): Updated results from a phase I/II study. J Clin Oncol 2008, 26(Suppl):Abstr 16014.

Pre-publication history

The pre-publication history for this paper can be accessed here: http://www.biomedcentral.com/1471-2407/10/695/prepub

\footnotetext{
doi:10.1186/1471-2407-10-695

Cite this article as: Gruenwald et al:: Circulating endothelial cells are an early predictor in renal cell carcinoma for tumor response to sunitinib. BMC Cancer 2010 10:695.
}

\section{Submit your next manuscript to BioMed Central} and take full advantage of:

- Convenient online submission

- Thorough peer review

- No space constraints or color figure charges

- Immediate publication on acceptance

- Inclusion in PubMed, CAS, Scopus and Google Scholar

- Research which is freely available for redistribution

Submit your manuscript at www.biomedcentral.com/submit
C Biomed Central 